\title{
Vascular miR-181b controls tissue factor-dependent thrombogenicity and inflammation in type 2 diabetes
}

\author{
Marco Witkowski ${ }^{1 \dagger}$, Mario Witkowski ${ }^{2+}$, Mona Saffarzadeh ${ }^{3}$, Julian Friebel ${ }^{1}$, Termeh Tabaraie ${ }^{1}$, Loc Ta Bao ${ }^{1}$, \\ Aritra Chakraborty ${ }^{1}$, Andrea Dörner ${ }^{1}$, Bernd Stratmann ${ }^{4}$, Diethelm Tschoepe ${ }^{4}$, Samantha J. Winter ${ }^{5}$, \\ Andreas Krueger ${ }^{5}$, Wolfram Ruf ${ }^{3}$, Ulf Landmesser ${ }^{1}$ and Ursula Rauch ${ }^{1 *}$ (])
}

\begin{abstract}
Background: Diabetes mellitus is characterized by chronic vascular inflammation leading to pathological expression of the thrombogenic full length (fl) tissue factor (TF) and its isoform alternatively-spliced (as) TF. Blood-borne TF promotes factor ( $F$ ) Xa generation resulting in a pro-thrombotic state and cardiovascular complications. MicroRNA (miR)s impact gene expression on the post-transcriptional level and contribute to vascular homeostasis. Their distinct role in the control of the diabetes-related procoagulant state remains poorly understood.
\end{abstract}

Methods: In a cohort of patients with poorly controlled type 2 diabetes $(n=46)$ plasma levels of miR-181b were correlated with TF pathway activity and markers for vascular inflammation. In vitro, human microvascular endothelial cells (HMEC)-1 and human monocytes (THP-1) were transfected with miR-181 b or anti-miR-181b and exposed to tumor necrosis factor (TNF) a or lipopolysaccharides (LPS). Expression of TF isoforms, vascular adhesion molecule (VCAM) 1 and nuclear factor (NF) KB nuclear translocation was assessed. Moreover, aortas, spleen, plasma, and bone marrowderived macrophage (BMDM)s of mice carrying a deletion of the first miR-181b locus were analyzed with respect to TF expression and activity.

Results: In patients with type 2 diabetes, plasma miR-181 b negatively correlated with the procoagulant state as evidenced by TF protein, TF activity, D-dimer levels as well as markers for vascular inflammation. In HMEC-1, miR-181b abrogated TNFa-induced expression of fTF, asTF, and VCAM1. These results were validated using the anti-miR-181b. Mechanistically, we confirmed a miR-181b-mediated inhibition of importin-a3 (KPNA4) leading to reduced nuclear translocation of the TF transcription factor NFKB. In THP-1, miR-181 b reduced both TF isoforms and FXa generation in response to LPS due to targeting phosphatase and tensin homolog (PTEN), a principal inducer for TF in monocytes. Moreover, in miR-181-/- animals, we found that reduced levels of miR-181 b were accompanied by increased TF, VCAM1, and KPNA4 expression in aortic tissue as well as increased TF and PTEN expression in spleen. Finally, BMDMs of miR-181-/- mice showed increased TF expression and FXa generation upon stimulation with LPS.

Conclusions: miR-181b epigenetically controls the procoagulant state in diabetes. Reduced miR-181b levels contribute to increased thrombogenicity and may help to identify individuals at particular risk for thrombosis.

\footnotetext{
*Correspondence: ursula.rauch@charite.de

${ }^{\dagger}$ Marco Witkowski and Mario Witkowski contributed equally to this work

${ }^{1}$ Charité Centrum 11, Department of Cardiology, Charité -

Universitätsmedizin Berlin, Campus Benjamin Franklin, Hindenburgdamm

30, 12200 Berlin, Germany

Full list of author information is available at the end of the article
}

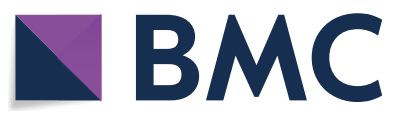

(c) The Author(s) 2020. This article is licensed under a Creative Commons Attribution 4.0 International License, which permits use, sharing, adaptation, distribution and reproduction in any medium or format, as long as you give appropriate credit to the original author(s) and the source, provide a link to the Creative Commons licence, and indicate if changes were made. The images or other third party material in this article are included in the article's Creative Commons licence, unless indicated otherwise in a credit line to the material. If material is not included in the article's Creative Commons licence and your intended use is not permitted by statutory regulation or exceeds the permitted use, you will need to obtain permission directly from the copyright holder. To view a copy of this licence, visit http://creativeco mmons.org/licenses/by/4.0/. The Creative Commons Public Domain Dedication waiver (http://creativecommons.org/publicdomain/ zero/1.0/) applies to the data made available in this article, unless otherwise stated in a credit line to the data. 
Keywords: Diabetes mellitus, Diabetes complications, Thrombosis, Tissue factor, microRNA, Vascular homeostasis, Endothelial cells, Monocytes, PTEN, NFKB

\section{Background}

Under diabetic conditions, chronic inflammatory signaling in the vasculature sustains endothelial dysfunction, leukocyte infiltration, and a pro-thrombotic environment $[1,2]$.

Tissue factor (TF), the membrane-bound receptor for coagulation factor (F) VIIa, is constitutively expressed in the perivascular space but under physiological conditions not present in the vasculature or blood [3]. However, hyperglycemia and pro-inflammatory molecules, such as tumor necrosis factor (TNF) $\alpha$ or lipopolysaccharides (LPS), induce the highly thrombogenic full length (fl) TF and its less thrombogenic isoform alternativelyspliced (as) TF [4-6]. Vessel wall-derived flTF mainly drives inflammatory signaling via protease-activated receptor (PAR)s [7-9], can lead to vascular dysfunction under oxidative stress [10], and may contribute to atherothrombosis through release in TF-positive procoagulant microvesicles (MVs) [11, 12]. In the blood, hematopoietic cells, including monocytes and macrophages, and their released procoagulant MVs represent the main source of TF $[13,14]$. When in contact with blood, flTF triggers the FVIIa-dependent generation of FXa prompting thrombin accumulation and clotting [15]. Particularly, patients with poorly controlled diabetes show pathological TF activity in the blood accounting for vascular complications [16].

Recently, a critical role of microRNA (miR)s in the pathogenesis of cardiovascular diseases (CVD) and diabetes-related complications has been demonstrated [17-19]. Binding of specific target transcripts by miRs leads to mRNA degradation and translational repression. We have recently shown that miR-126 and miR19a target the TF transcript thereby contributing to the epigenetic control of vascular inflammation and coagulation [20,21]. Thus, a procoagulant state in diabetes can also be considered a result of a defective miR-mediated control of coagulation factors.

Among endothelial miRs, miR-181b emerged as a powerful regulator of vascular homeostasis. Several lines of evidence point to implication of miR-181b into TF-related thrombogenicity: In endothelial cells (ECs) in vitro, miR-181b targets importin- $\alpha 3$ (KPNA4) and thereby reduces nuclear translocation of nuclear factor (NF) $\mathrm{kB}$, one of the main transcription factors for vascular TF expression [22]. Moreover, Henao Mejia et al. found that miR-181b targets phosphatase and tensin homolog (PTEN), a principal inducer for TF expression in hematopoietic cells [23]. In monocytes, PTEN drives LPS-induced TF expression by negatively regulating the phosphoinositide 3-kinase (PI3K)/AKT pathway. Accordingly, PTEN-/- mice exhibit reduced TF activity [24]. In vivo, Lin et al. reported that miR-181b administration reduced arterial thrombosis in a photochemical injury-model [25], a feature that is also observed in mice with reduced vascular TF expression [26, 27]. Finally, miR-181b expression is lowered via hyperglycemia and pro-inflammatory cytokines that are all known to induce TF expression in the vasculature [28].

In the present study, we sought to assess the role of miR-181b in the hemostatic balance in advanced diabetes.

In a cohort of patients with poorly controlled type 2 diabetes, we provide novel evidence that miR-181b expression strongly correlates with reduced activation of the TF-pathway assessed by TF protein, TF activity, and D-dimer levels as well as reduced vascular inflammation. In vitro, TF expression and FXa generation was reduced by miR-181b in human ECs and monocytes. Using animals with a deletion of the first miR-181b locus we provide in vivo evidence that miR-181b contributes to the control of vascular TF activity derived from the endothelium and hematopoietic cells. Our data suggests that the epigenetic control by circulating miR-181b is essential to ensure the hemostatic balance by reducing inflammation-driven vascular TF expression.

\section{Research design and methods Patient study}

The study protocol was approved by the local ethics committee and was performed in accordance to the ethics principles in the Declaration of Helsinki. Prior to participation in the study, each patient gave a written informed consent. 46 patients with known diabetes mellitus type 2 admitted for poor glycemic control at the Diabetes Center NRW Bad Oeynhausen, Germany, were included in the study. Table 1 shows the patient characteristics.

\section{Animals}

Tissues and cells from age- and sex-matched 12-16 weeks old miR-181a/b-1-/- mice (B6.Mirc14 ${ }^{\mathrm{tm} 1.1 \mathrm{Ankr}}$ as already described [29], termed "miR-181-/-" throughout this article) were kindly provided by Andreas Krueger, Institute for Molecular Medicine in Frankfurt, Germany). These mice carry a constitutive deletion of miR-181a1 and miR-181b1 and were housed under specific pathogen 
Table 1 Patient characteristics

\begin{tabular}{|c|c|c|c|}
\hline $\begin{array}{l}\text { Patient characteristics } \\
n=46\end{array}$ & $\begin{array}{l}\text { Mean } \pm S D \text {, median }[\mathrm{IQR}] \\
\text { or percentage }\end{array}$ & $\begin{array}{l}\text { Correlation coefficient vs. miR- } \\
181 \mathrm{~b}\end{array}$ & $p$-value \\
\hline Age (years) & $65.6 \pm 9.3$ & -0.053 & 0.722 \\
\hline Female gender (\%) & 26.0 & 0.011 & 0.941 \\
\hline $\mathrm{BMI}\left(\mathrm{kg} / \mathrm{m}^{2}\right)$ & $30.6[27.75-35.25]$ & 0.203 & 0.175 \\
\hline Minimal fasting blood glucose (mg/dL) & $93.0[75.75-128.3]$ & -0.105 & 0.485 \\
\hline Maximal fasting blood glucose $(\mathrm{mg} / \mathrm{dL})$ & $197.5[140.5-238.8]$ & 0.146 & 0.332 \\
\hline Average fasting blood glucose (mg/dL) & $139.1[117.8-166.5]$ & -0.012 & 0.934 \\
\hline $\mathrm{HbA1c}(\%)$ & $8.39 \pm 1.61$ & 0.2895 & 0.051 \\
\hline $\mathrm{HbA} 1 \mathrm{c}(\mathrm{mmol} / \mathrm{mol})$ & $68.1 \pm 17.7$ & 0.2895 & 0.051 \\
\hline $\mathrm{CRP}(\mathrm{mg} / \mathrm{dL})$ & $0.40[0.14-0.64]$ & -0.051 & 0.733 \\
\hline Leukocytes (N/nL) & $7.4[6.37-9.12]$ & -0.295 & $0.045^{*}$ \\
\hline Neutrophils (\%) & 59.4 [52.03-66.65] & -0.318 & $0.031^{*}$ \\
\hline Monocytes (\%) & $6.83 \pm 2.29$ & 0.028 & 0.850 \\
\hline D-Dimers (ng/mL) & $377.8[247.4-523.5]$ & -0.343 & $0.019^{*}$ \\
\hline Hemoglobin (g/dL) & $14.0 \pm 1.2$ & -0.089 & 0.555 \\
\hline Homocysteine ( $\mu \mathrm{mol} / \mathrm{L})$ & $12.5[10.95-17.08]$ & 0.071 & 0.637 \\
\hline thrombocytes $(\mathrm{N} / \mathrm{nL})$ & $211.9 \pm 51.7$ & -0.226 & 0.130 \\
\hline Triglycerides (mg/dL) & $186[110.3-271.0]$ & 0.222 & 0.136 \\
\hline LDL cholesterol (mg/dL) & 113 [88-135] & 0.043 & 0.796 \\
\hline miR-181b-5p & $0.169[0.014-0.470]$ & 1 & \\
\hline hypertension (\%) & 100 & & \\
\hline CAD (\%) & 41.3 & -0.177 & 0.236 \\
\hline PAD (\%) & 26.0 & -0.096 & 0.521 \\
\hline carotid stenosis (\%) & 8.6 & -0.133 & 0.375 \\
\hline history of stroke (\%) & 10.8 & -0.249 & 0.094 \\
\hline History of myocardial infarction (\%) & 15.2 & -0.006 & 0.964 \\
\hline \multicolumn{4}{|l|}{ Medication } \\
\hline Insulin (\%) & 69.5 & -0.135 & 0.370 \\
\hline Metformin (\%) & 50.0 & 0.462 & $<0.001^{*}$ \\
\hline Sulfonylurea (\%) & 17.3 & -0.146 & 0.330 \\
\hline Statin (\%) & 50.0 & -0.040 & 0.787 \\
\hline Diuretics (\%) & 60.8 & 0.164 & 0.274 \\
\hline ACE inhibitor (\%) & 47.8 & 0.114 & 0.447 \\
\hline Angiotensin receptor blocker (\%) & 28.2 & 0.194 & 0.194 \\
\hline Aldosterone antagonist (\%) & 8.6 & -0.017 & 0.908 \\
\hline Calcium antagonist (\%) & 17.3 & -0.177 & 0.239 \\
\hline Nitrate vasodilators (\%) & 13.0 & -0.034 & 0.822 \\
\hline Acetylsalicylic acid (\%) & 58.7 & -0.021 & 0.886 \\
\hline Beta-blocker (\%) & 50.0 & 0.194 & 0.194 \\
\hline
\end{tabular}

$\mathrm{N}=46$, shown are either Pearson or Spearman correlation coefficients for normally and not normally distributed continuous variables, respectively. For binary variables, a point-biserial correlation was performed. Values presented are mean $\pm S D$, medians [IQR] or percentages

$A C E$ angiotensin-converting enzyme, $B M I$ body mass index, CAD coronary artery disease, CRP c-reactive protein, HbA1c glycated hemoglobin, $L D L$ low-density lipoprotein, $M I$ myocardial infarction, $P A D$ peripheral artery disease, TF tissue factor

${ }^{*} \mathrm{p}<0.05$

free conditions in the central animal facility at the Institute for Molecular Medicine in Frankfurt, Germany.
ELISA experiments and glucose measurements

The protein plasma concentrations were assessed by using specific ELISA systems (Table 2) according to the 
Table 2 Material

\begin{tabular}{|c|c|}
\hline Application & Materials \\
\hline ELISA & TF ELISA kit (Sekisui), D-dimer ELISA kit (Diagnostica Stago), and TAT ELISA kit (Siemens Healthcare) \\
\hline Transfection & $\begin{array}{l}\text { Negative control mimic (Dharmacon), } 200 \text { nM miR-181b mimic (hsa-miR-181b-5p, HMI0270, Sigma), } 200 \text { nM anti-miR-181b (anti-hsa- } \\
\text { miR-181b-5p, HSTUD0270, Sigma), } 200 \text { nM inhibitor control (Dharmacon), siRNA against PTEN (L-003023-00-0005), (Dharmacon) or } \\
\text { a control siRNA (Dharmacon) }\end{array}$ \\
\hline Taqman PCR & $\begin{array}{l}\text { miR-181b-5p (001098), mouse asTF (custom-made), mouse flTF (Mm00438856_m1), human VCAM1 (Hs01003372), mouse VCAM1 } \\
\text { (Mm00449197_m1), human PTEN (Hs01628827_s1), mouse PTEN (Mm00477208_m1), mouse KPNA4 (Mm00434725_m1), human } \\
\text { GAPDH (Hs99999905_m1), mouse GAPDH (Mm99999915_g1), U6snRNA (001973), and self-designed FAM-tagged TaqMan }{ }^{\circledR} \text { gene } \\
\text { expression assays for human flTF and asTF (for details see [44]) }\end{array}$ \\
\hline SYBR Green PCR & $\begin{array}{l}\text { Human GAPDH (forward 5'-AGCCACATCGCTCAGACAC-3', reverse 5'-GCCCAATACGACCAAATCC-3'), human KPNA4 Forward 5'-CAG } \\
\text { GAGATTCTTCCAGCCCTTTGTGT-3', Reverse 5'-ATTACCATCTGTATTTGTTCATTGCCAGCATC-3') }\end{array}$ \\
\hline Western blot & $\begin{array}{l}\text { Human flTF (Sekisui diagnostics, 4501, goat lgG), human asTF (monoclonal rabbit, kindly provided by Prof. Vladimir Bogdanov, Uni- } \\
\text { versity of Cincinnati), human VCAM1 (Cell signaling, 13662S, rabbit IgG), human-KPNA4 (Abcam, ab6039, goat IgG), human PTEN } \\
\text { (Cell signaling, 9559, rabbit IgG), human p-NFkB (Cell signaling, 3033, rabbit IgG), human NFkB (Santa Cruz, sC-109, rabbit IgG), } \\
\text { human histone H3 (Cell signaling, 9715, rabbit), mouse and human GAPDH (Calbiochem, CB1001, mouse IgG), mouse TF (Sekisui } \\
\text { diagnostics, 4515, rabbit lgG), mouse VCAM1 (Cell signaling, 39036, rabbit IgG) }\end{array}$ \\
\hline IFA & $\begin{array}{l}\text { Mouse TF (Sekisui diagnostics, 4515, rabbit IgG), mouse VCAM1 (Cell signalling, 39036, rabbit IgG), Goat anti Rabbit (Dianova), DAPI } \\
\text { (Invitrogen), F-actin probe, Alexa Fluor } 647 \text { Phalloidin (Thermo Fisher, A12379) }\end{array}$ \\
\hline
\end{tabular}

manufacturer's instructions. Fasting blood glucose levels in patients were measured by a standardized laboratory test, while further glucose levels during the day were obtained by a finger-prick test from capillary blood.

\section{TF activity}

The measurement of TF activity was performed as described before [2]. The recombinant FVIIa was kindly provided by Novo Nordisk.

\section{Cell culture}

HMEC from ATCC were maintained in MCBD 131 medium (Gibco) supplemented with 10\% FBS (Gibco), $100 \mathrm{U} / \mathrm{mL}$ penicillin/streptomycin (PAA), $2 \mathrm{mM} \mathrm{L-glu-}$ tamin (PAA), and $0.05 \mathrm{mg} / \mathrm{mL}$ hydrocortison. HMEC were used for experiments until the 13th passage. THP-1 cells from ATCC were grown in RPMI 1640 medium (Gibco) supplemented with 10\% FBS and 1\% penicillin/ streptomycin.

\section{Transfection and stimulation experiments}

HMEC-1 and THP-1 were transfected with $200 \mathrm{nM}$ of the oligonucleotides listed in Table 2 using the siRNA transfection reagent interferin (VWR) according to manufacturer's protocol. $24 \mathrm{~h}$ post transfection cells were starved in MCBD 131 medium (Gibco) for $2 \mathrm{~h}$ and then stimulated with $10 \mathrm{ng} / \mathrm{mL}$ TNF $\alpha$ for $2 \mathrm{~h}$ for gene expression analysis and $6 \mathrm{~h}$ or $24 \mathrm{~h}$ for TF or VCAM1 protein expression, respectively. THP-1 cells were stimulated with LPS $(10 \mu \mathrm{g} /$ $\mathrm{mL}$, Sigma) for $2 \mathrm{~h}$ for mRNA expression analysis and $6 \mathrm{~h}$ for assessment of TF activity. For siRNA-mediated knock down experiments THP-1 were transfected for $48 \mathrm{~h}$.

\section{Real time PCR}

For real-time PCR, total mRNA was isolated from cultured cells and murine tissue with peqGOLD Trifast (Peqlab) and for patient blood plasma using the mirVana Paris Kit (Life Technologies). Gene expression was determined using GoTaq ${ }^{\circledR}$ Probe qPCR Master Mix (Promega) with FAM-tagged TaqMan ${ }^{\circledR}$ gene expression assays (life Technologies) or via SYBR Green assays using SYBR ${ }^{\circledR}$ Select Master Mix (applied Biosystems) with specific primers (Table 2). Relative gene expression was determined via the comparative $\mathrm{C}(\mathrm{t})(\Delta \Delta \mathrm{Ct})$ method with GAPDH or $18 \mathrm{~S}$ ribosomal RNA as endogenous control for mRNA and U6 snRNA for miR.

\section{Western blot}

Western blots were performed as described before [3]. Nuclear and cellular lysates were isolated using the NE$\mathrm{PER}^{\mathrm{TM}}$ Nuclear and Cytoplasmic Extraction Reagents (Thermo Fisher Scientific) following the manufacturer's instructions. Antibodies used are listed in Table 2. The western blots have been performed $\geq 3$ times.

\section{Immunofluorescence}

For protein staining aortas and spleen were embedded in Tissue-Tek and immunofluorescence was performed with specific antibodies and probes (Table 2).

\section{Whole blood microvesicle-associated FXa generation}

TF activity of whole blood mouse MVs was assessed as previously described [4]. Briefly, whole blood was drawn 
by vena cava puncture and $10 \%$ citrate added. The cell counts for normalization of the TF activity to the monocyte count was done with a Vetscan automated cell counter. The whole blood was stimulated with $10 \mu \mathrm{g} / \mathrm{mL}$ LPS for $4 \mathrm{~h}$ to induce MV release and centrifuged $2 \times$ at $3000 \mathrm{~g}$. The plasma was centrifuged again for $40 \mathrm{~min}, 4{ }^{\circ} \mathrm{C}$, at $18000 \mathrm{~g}$ to isolate MVs. MV TF activity was determined by adding $2 \mathrm{nM}$ mouse recombinant FVIIa (kindly provided by $\mathrm{H}$. Ostergaard, Novo Nordisk) and $50 \mathrm{nM}$ FX (Haematologic Technologies) to resuspended MVs in HBS (10 mM Hepes, pH 7.4, $137 \mathrm{mM} \mathrm{NaCl}, 5.3 \mathrm{mM} \mathrm{KCl}$, $1.5 \mathrm{mM} \mathrm{CaCl} 2)$. FXa was measured by using the chromogenic substrate Spectrozyme FXa (Sekisui Diagnostics).

\section{Culture of bone marrow-derived macrophages (BMDMs)}

BMDMs were in vitro-differentiated as described before [5]. Briefly, isolated bone marrow cells were cultivated in DMEM supplemented with $20 \% \mathrm{~L}$ cell medium, $10 \%$ FCS, $1 \mathrm{mM}$ L-glutamine, penicillin, and streptomycin. On day 7 macrophages were seeded at a density of $1 \times 10^{6}$ per well. On the next day, macrophages were stimulated with $1 \mu \mathrm{g} / \mathrm{mL}$ LPS (Enzo Life Sciences) for $4 \mathrm{~h}$. The cells were then lysed for RNA analysis, western blot or measurement of FXa generation as described above.

\section{Statistical analysis}

The statistical analyses were performed using the software GraphPad Prism 7. Correlation of patient characteristics were performed via Pearson correlation for normally distributed values or Spearman correlation in case of not normal distribution. For binary variables, a point-biserial correlation was performed. Differences between 2 groups were examined using a Mann-Whitney test or student's t test (2-tailed). For comparisons of 1 parameter between more than two related groups the one-way ANOVA test with Dunn's multiple comparison as post hoc test was used. For data sets with 4 groups and 2 variables a 2-way ANOVA test with Sidak's multiple comparison post hoc test was performed. Data are represented as mean \pm SEM. p-values $<0.05$ are considered statistically significant.

\section{Results}

We hypothesized an association of miR-181b with vascular TF expression in the setting of diabetes. Therefore, 46 patients with type 2 diabetes admitted to a diabetes center because of insufficient glycemic control (mean $\mathrm{HbA} 1 \mathrm{c} 8.39 \pm 1.61 \%$ or $68.1 \pm 17.7 \mathrm{mmol} / \mathrm{mol}$ ) were enrolled in the study. Compared to healthy control subjects with normal TF protein levels in the plasma (median TF protein $102.2 \mathrm{pg} / \mathrm{mL}$ [Q1 75.8, Q3 136.1], Additional file 1: Table S1), the enrolled diabetics presented a prothrombotic state (median TF protein $291.3 \mathrm{pg} / \mathrm{mL}$ [Q1
165.3, Q3 373.9] and median TF activity $496.8 \mathrm{U} / \mathrm{mL}$ [Q1 293.4, Q3 727.7]). No association of miR-181b with blood glucose levels was observed. However, circulating miR$181 \mathrm{~b}$ showed a strong negative correlation with TF protein (Fig. 1a, $\mathrm{r}=-0.48, \mathrm{p}<0.001$ ) and TF activity (Fig. 1b, $\mathrm{r}=-0.82, \mathrm{p}<0.0001)$. Moreover, miR-181b correlated with reduced levels of $\mathrm{D}$-dimers of the TF pathway $(\mathrm{r}=-0.34, \mathrm{p}<0.05$, Table 1$)$. Furthermore, miR-181b was related to a lower grade of inflammation as evidenced by a negative correlation with fibrinogen and leukocyte count (Fig. 1c, d). In line with this, miR-181b was positively associated with metformin treatment that is known to reduce vascular inflammation $(\mathrm{r}=0.462, \mathrm{p}<0.001$, Table 1). Plasma miR-181b also correlated with the antithrombotic miR-126 and miR-19a $(r=0.79, p<0.0001$ and $r=0.73, p<0.0001$, respectively, Fig. 1e, f).

In human microvascular endothelial cells (HMEC)-1, hyperglycemia and the pro-inflammatory cytokine TNF $\alpha$ reduced miR-181b levels, whereas it induced both TF isoforms and the NFkB-dependent vascular cell adhesion molecule (VCAM) 1 (Additional file 2: Figure S1A-H). We analyzed the effect of miR-181b on the inflammationinduced TF expression in ECs. HMEC-1 were therefore transfected with miR-181b or anti-miR-181b as well as the appropriate controls and stimulated with $10 \mathrm{ng} /$ mL TNF $\alpha$. In miR-181b transfected cells, we observed a reduction of both TF isoforms on the mRNA and protein level in cells stimulated with TNF $\alpha$ for $2 \mathrm{~h}$ and $6 \mathrm{~h}$, respectively, whereas anti-miR-181b increased asTF and flTF expression under inflammatory conditions (Fig. 2ae). We confirmed that miR-181b reduces and anti-miR181b induces VCAM1 in HMEC-1 (Fig. 2f-h). As the mechanism for inhibition of TNF $\alpha$-induced TF expression we found a downregulation of KPNA4 in HMEC-1 mRNA and protein (Additional file 3: Figure S2A, B) consistent with a decrease in NFKB nuclear translocation exhibited by miR-181b (Fig. 2i).

To assess whether miR-181b also reduces TF expression in human monocytes, the main source of TF activity in the blood, THP-1 cells were transfected with miR-181b and then stimulated with LPS to induce TF expression. Due to the low endogenous expression level of miR-181b in monocytes, a gain of function approach was used. We found that miR-181b reduced mRNA levels of both TF isoforms (Fig. 3a, b) and FXa generation (Fig. 3c) following LPS treatment of THP-1. In contrast to ECs, LPS-induced $\mathrm{NF}_{\mathrm{K} B}$ was not restricted to the cytoplasmatic compartment in THP-1 (Fig. 3d, upper panel) nor were KPNA4 mRNA levels reduced by miR181b (Fig. 3e). However, miR-181b led to a marked reduction in NFKB phosphorylation and subsequent nuclear translocation (Fig. 3d, both panels) suggesting an upstream effect on NFKB activation. We suspected 

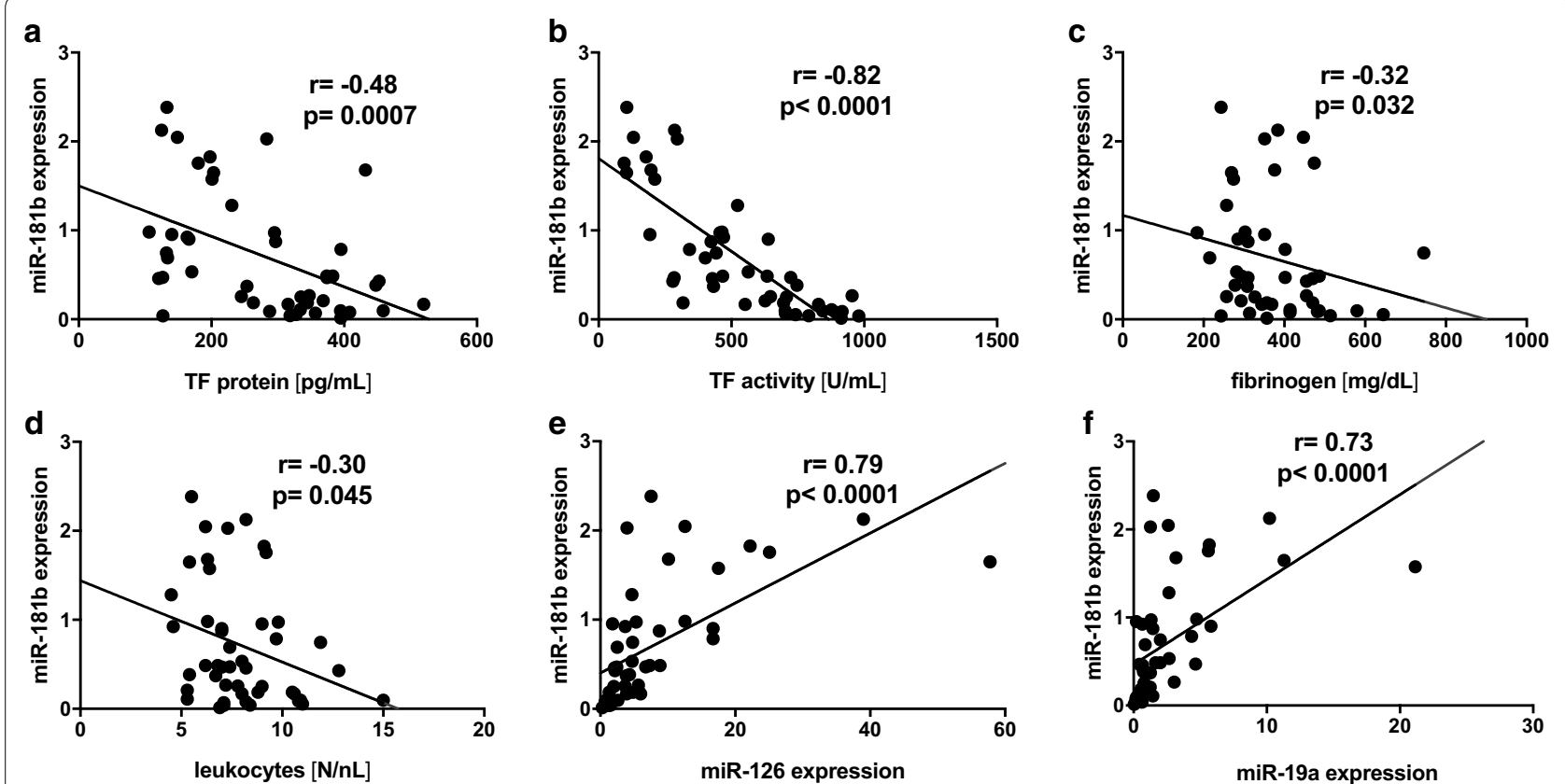

Fig. 1 Plasma miR-181b correlates with reduced tissue factor activity and inflammation in diabetes. Plasma of patients with diabetes was analyzed with respect to miR-181b expression. Circulating miR-181b negatively correlated with TF protein (a) as well as TF activity (FXa generation) (b). Moreover, miR-181b expression was related to lower levels of the pro-inflammatory fibrinogen (c) and lower leukocyte counts (d). We also observed a correlation of miR-181b with the TF-specific miR-126 (e) and miR-19a (f). $n=46$. Upon normality testing a Spearman or Pearson correlation was performed, r-values and p-values are indicated

that control of PTEN expression may contribute to the miR-181b-mediated reduction of TF activity in monocytes. Indeed, PTEN expression was reduced in THP-1 cells transfected with miR-181b (Fig. 3f, g). siRNAmediated knock down of PTEN reduced LPS-induced expression of flTF and asTF in THP-1 and phenocopied the miR-181b effect (Fig. 3h-j).

To assess the significance of our experimental findings in vivo, animals carrying a deletion of the first miR-181b locus (as well as miR-181a-1; B6.Mirc14 ${ }^{\text {tm1.1Ankr }}$, here referred to as miR-181-/- mice) with reduced vascular miR-181b expression were analyzed (Fig. 4a). While no change for asTF mRNA was observed, we found an increase in flTF mRNA and protein expression in miR181-/- aortas as compared to wt mice, (Fig. 4b-d). Immunofluorescence using a murine TF-specific antibody revealed that the rise in TF protein in miR-181-/aortas originated from the endothelial layer (Fig. 4e, upper panel). Moreover, expression of KPNA4 (Fig. 4f) as well as VCAM1 mRNA and protein (Fig. 4g, h, e lower panel) were increased in aortas of miR-181-/- animals. To assess TF expression in hematopoietic cells, the spleen of miR-181-/- mice was analyzed. Here, miR-181b was reduced (Additional file 5: Figure S4a) while both TF isoforms and PTEN mRNA were increased as compared to wt animals (Fig. $4 \mathrm{i}-\mathrm{m}$ ).
To investigate the blood procoagulant activity of miR181b-/ - animals, whole blood was stimulated with LPS and the FXa generation of MVs assessed. We did not observe a difference in MV-associated FXa generation between blood of wt and ko animals (Additional file 5: Figure S4B). In line, no differences in plasma thrombin anti-thrombin complexes was seen between wt and ko animals (Additional file 5: Figure S4C). However, isolated bone marrow-derived macrophages (BMDM), that have been shown to contribute to blood thrombogenicity, showed a strong reduction in miR-181b expression in the miR-181-/- animals (Fig. 5a) and exhibited higher levels of asTF and flTF mRNA (Fig. 5b, c) as well as more TF protein and FXa generation (Fig. $4 \mathrm{~d}$, e) in response to LPS than wt cells.

\section{Discussion}

Here, we report that miR-181b controls thrombogenicity in the vasculature and correlates with reduced circulating TF and vascular inflammation in patients with diabetes. Using human ECs and monocytic cells, we demonstrate that miR-181b reduces the inflammation-induced vascular TF expression and FXa generation. In a murine miR181 ko system, we provide in vivo evidence that loss of miR-181b promotes endothelial and hematopoietic TF expression. Our work demonstrates that miR-181b is a 


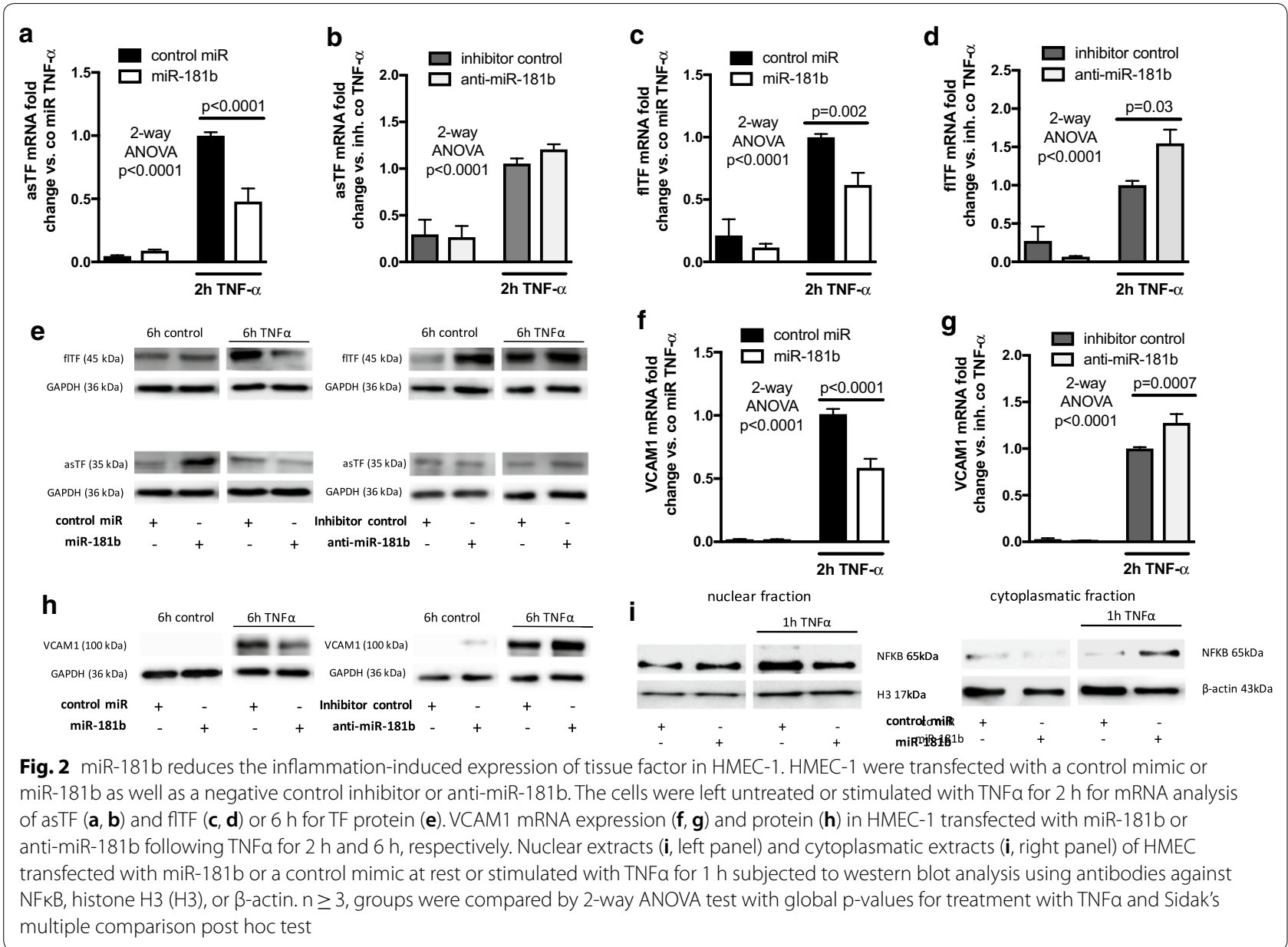

pivotal regulator of thrombogenicity and contributes to vascular homeostasis in the presence of poorly controlled diabetes.

\section{Low miR-181b: association with a pro-thrombotic and pro-inflammatory state}

In the healthy vasculature, circulating miRs epigenetically control pro-inflammatory transcription factors and their gene products to preserve vascular homeostasis [3, 30-32]. However, in a diabetic environment this protective miR transcriptome is disrupted [33]. In particular, diabetes-related loss of TF-specific miRs, such as miR126 or miR-223 contributes to vascular inflammation and a pro-thrombotic state [33, 34].

Here we show that miR-181b, a key regulator for endothelial function, beta cell function, peripheral insulin sensitivity, and NFKB signaling [22, 28, 35], participates in the control of vascular TF activity in diabetes. In poorly controlled diabetics, miR-181b was associated with reduced activation of the TF pathway, lower leukocyte count, and fibrinogen, which both constitute independent risk factors for cardiovascular mortality among patients with diabetes [36].

In contrast to markers of inflammation, miR-181b levels did not correlate with blood glucose or HbA1c in our cohort. Although we and Sun et al. [28] found that miR181b expression in HMEC-1 and human umbilical vein endothelial cells (HUVEC) is reduced by high glucose concentrations, Yang et al. [37] reported activation of the miR-181a/b-specific transcription factor signal transducer and activator of transcription (STAT) 3 in HUVEC treated with sera from diabetics pointing to a more complex regulation of miR-181b expression in humans. This may explain why the miR-181b expression in our healthy controls did not differ from those in poorly controlled diabetes (Additional file 6: Figure S5A). In contrast, miR-126 that has been shown to be reduced in diabetes in the population-based Bruneck cohort, was significantly lower in our diabetes cohort compared to healthy controls confirming the quality of our measurements (Additional file 6: Figure S5B). We assume that diabetic 

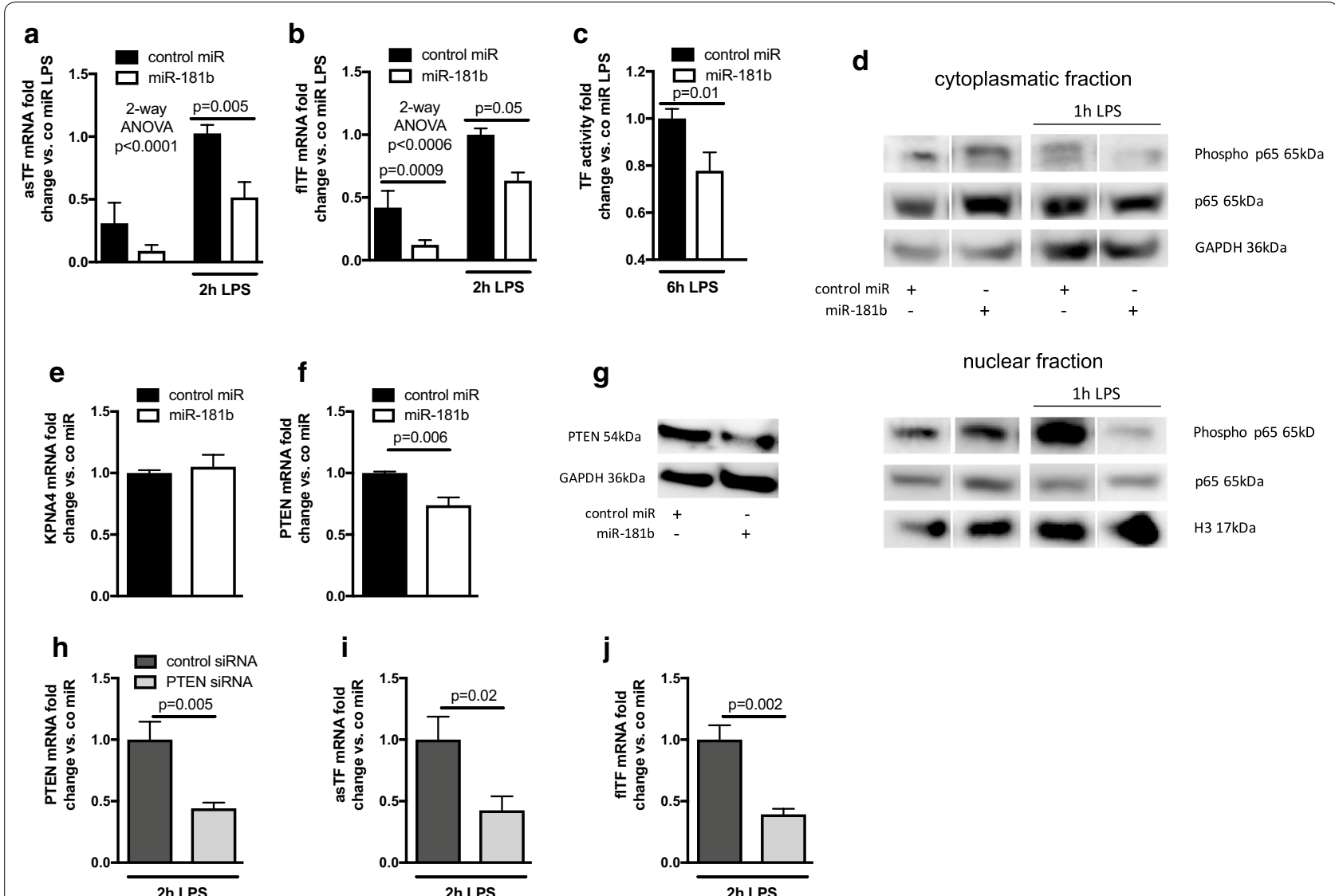

Fig. 3 miR-181 b inhibits LPS-induced tissue factor activity in THP-1. THP-1 cells were transfected with miR-181b and stimulated with LPS for $2 \mathrm{~h}$ to assess asTF and fITF mRNA $(\mathbf{a}, \mathbf{b})$ or $6 \mathrm{~h}$ for TF activity (c). THP-1 were transfected with a control mimic or miR-181b and then stimulated with LPS for $1 \mathrm{~h}$. Cytoplasmatic extracts (d, upper panel) and nuclear extracts (d, lower panel) were then subjected to western blot analysis using antibodies against phospho-NFkB (phospho p65), NFkB (p65), histone H3 (H3), or GAPDH (bands show samples with equal loading of the same gel. The original blots can be found in Additional file 3: Figure S3). KPNA4 mRNA (e), PTEN mRNA (f) and protein (g) in THP-1 transfected with a control miR or miR-181b. THP-1 were transfected with a control siRNA or siRNA against PTEN. PTEN knock down was confirmed via quantification of PTEN mRNA (h) and led to reduced mRNA levels of fTF (i) and asTF (j). $n \geq 3$, groups were compared by 2-way ANOVA test with global p-values for treatment with LPS and Sidak's multiple comparison post hoc test $(\mathbf{a}, \mathbf{b})$ or student's t-test

conditions beyond glycemia impact miR-181b expression resulting in differential expression levels among diabetics. Although we cannot rule out an impact of co morbidities and anti-diabetic drugs on miR-181b expression in our cohort, it seems likely that chronic inflammation in an advanced state of the disease is a more relevant factor than blood glucose for miR-181b suppression. In accordance, we found co expression of miR-181b with miR-126 and miR-19a that are both reduced by inflammatory cytokines $[20,21]$.

TF in the endothelium is reduced by $\mathrm{miR}-181 \mathrm{~b}$ under inflammatory conditions

Our data indicates that miR-181b restrains NFkBdepending TF expression in human and murine ECs via targeting of KPNA4. The direct contribution of vessel wall-derived TF to thrombosis has been a matter of debate [4]. Yet, through allosteric activation of FVIIa and/ or FXa generation, TF promotes pro-inflammatory PAR signaling leading to sustained vascular dysfunction. Consequently, an EC-specific deletion of TF reduced circulating inflammatory cytokines [38]. Recently, clinical trials provided strong evidence that the TF/VIIa/Xa pathway contributes to vascular complications and pharmacological blockage of FXa at low doses prevented ischemic CVD endpoints [39]. However, inhibition of vascular TF and PARs are challenged by bleeding issues due to their role in hemostasis and platelet function, respectively [40]. Our study identifies miR-181b as a potent regulator for pathological TF-induced vascular inflammation. Further clinical research needs to assess the therapeutic potential of miR-181b in the setting of diabetes and CVD. 


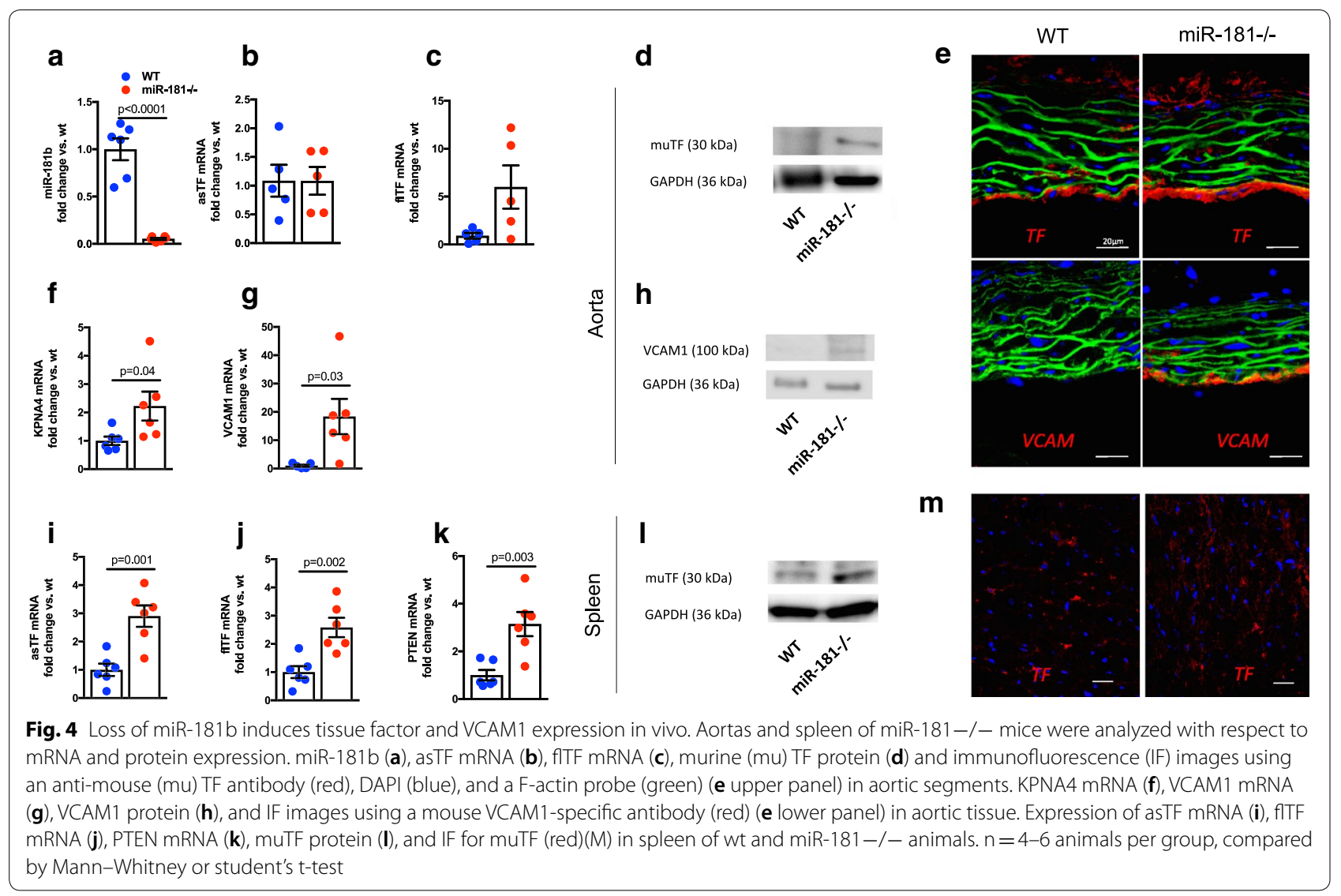

\section{Endothelial miR-181b governs hematopoietic TF activity via PTEN}

In the vasculature, hematopoietic cells represent the main pool of circulating TF and contribute to thrombosis $[13,26]$. Here, we show that miR-181b reduces TF activity in human monocytes through control of PTEN.

The strong negative correlation of circulating miR-181b with plasma TF activity in our patient cohort suggests that the mostly endothelial-derived miR-181b impacts monocytic TF production in humans. Recent studies reported that ECs can modulate the phenotype of monocytes via release of endothelial MVs. Njock et al. [41] showed that miR-181b along with other anti-inflammatory miRs is enriched in EC-derived MVs. Treatment of recipient THP-1 with EC-MVs or with miR-181b mimics repressed LPS-induced inflammatory gene expression in monocytes. These data along with our study highlight that endothelial miR-181b exerts anti-thrombotic properties beyond the vasculature by also modulating the thrombotic phenotype of monocytic cells and support the hypothesis that the endothelium at least indirectly participates in the regulation of plasma TF activity.

In contrast to ECs, miR-181b did not alter $N_{k} B$ nuclear translocation in human monocytes. Different host cell factors that preclude down regulation of KPNA4 may explain this observation. However, we are the first to show that miR-181b controls upstream NFKB activation in monocytes via targeting PTEN. The PI3K/AKT pathway was previously shown to negatively regulate LPSinduced TF transcription in human monocytes through downstream control of NFKB along with the TF-specific transcription factors activator protein (AP)-1 and early growth response (EGR)-1 [42]. Consequently, targeting of the PI3K/AKT negative regulator PTEN by miR-181b reduces LPS-induced TF expression and possibly other inflammatory factors.

\section{Differences of miR-181b's effect in the murine system}

In the murine system, miR-181b deficiency failed to alter monocyte-derived MV-TF activity but increased TF expression in spleen and BMDM.

In line with previous reports showing that miR-181b does not alter NFKB reporter activity of mouse peripheral blood mononuclear cell (PBMC)s [32], we did not observe changes in MV-associated monocytic TF activity or TAT levels. As suggested by Sun et al., differential expression of importin isoforms in mouse monocytes may be the underlying cause. However, our study shows 

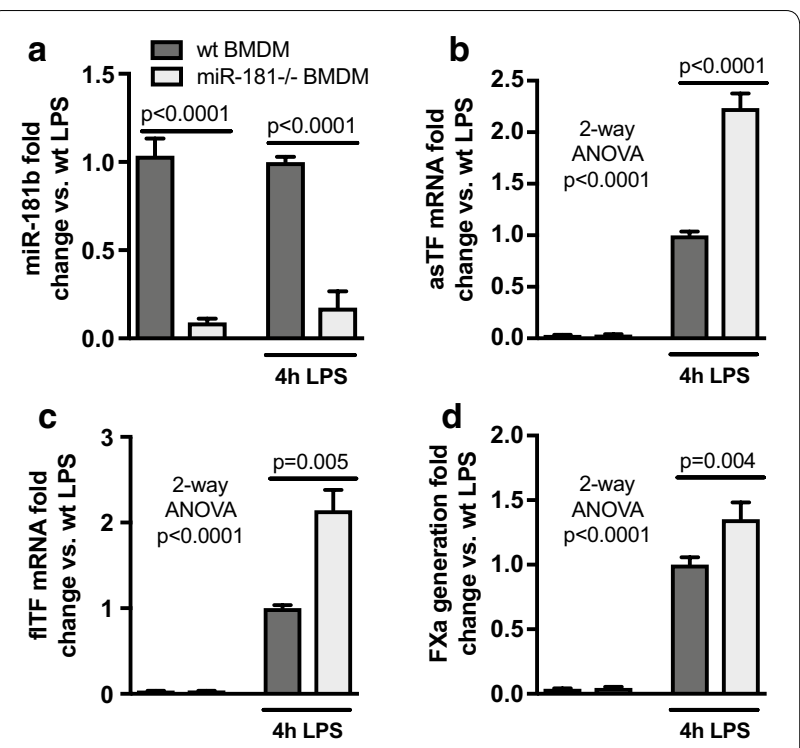

e

muTF (30 kDa)

GAPDH (36 kDa)

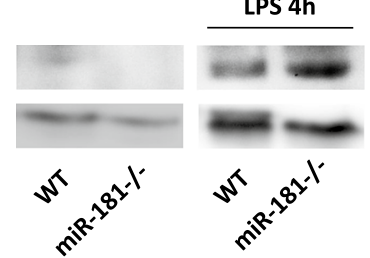

Fig. 5 miR-181b deletion in bone marrow-derived macrophages leads to increased TF expression and FXa generation upon inflammation. Bone marrow-derived macrophages (BMDM) were isolated from wt mice or miR-181-/- animals and cultured. The cells were either left untreated or stimulated with $1 \mu \mathrm{g} / \mathrm{mL}$ LPS for $4 \mathrm{~h}$. Next, the miR-181 b expression (a), asTF mRNA (b), fTTF mRNA (c), FXa generation (d), and muTF protein (e) were measured. $n=3-6$ animals per group, groups were compared by 2-way ANOVA test with global p-values for treatment with LPS and Sidak's multiple comparison post hoc test that miR-181b reduces hematopoietic TF production in murine BMDM. Macrophages not only produce TF-positive thromboinflammatory MVs [14] but also account for TF accumulation in atherosclerotic plaques [43]. Reduced TF expression in macrophages may contribute to the observation that miR-181b overexpression in Apo E-/- mice protects from atherosclerosis [32].

\section{Limitations}

miR expression in patient plasma samples was normalized to U6 which can be altered in some diseases. However, this has not been reported in patients with diabetes and our expression profiles in both cohorts are in accordance with previously published data [34]. Moreover, the miR-181-/- mouse model analyzed here carries a deletion of miR-181b-1 and the adjacent miR-181a-1 as well. Due to transcriptional co-regulation and high sequence similarities both miRs share largely the same functions. Accordingly, some of our findings might also be explained by loss of miR-181a.

\section{Conclusions}

Our work shows that circulating miR-181b contributes to the control of diabetes-related thrombogenicity and vascular inflammation (Fig. 6). Low miR-181b expression may identify patients at particular risk for thromboembolic complications. Vice versa, posttranscriptional control of vascular TF expression by miR-181b represents a potential avenue to improve endothelial dysfunction and thrombosis risk without facing bleeding issues as observed by direct inhibition of inflammatory coagulation factors. Further clinical trials are warranted to

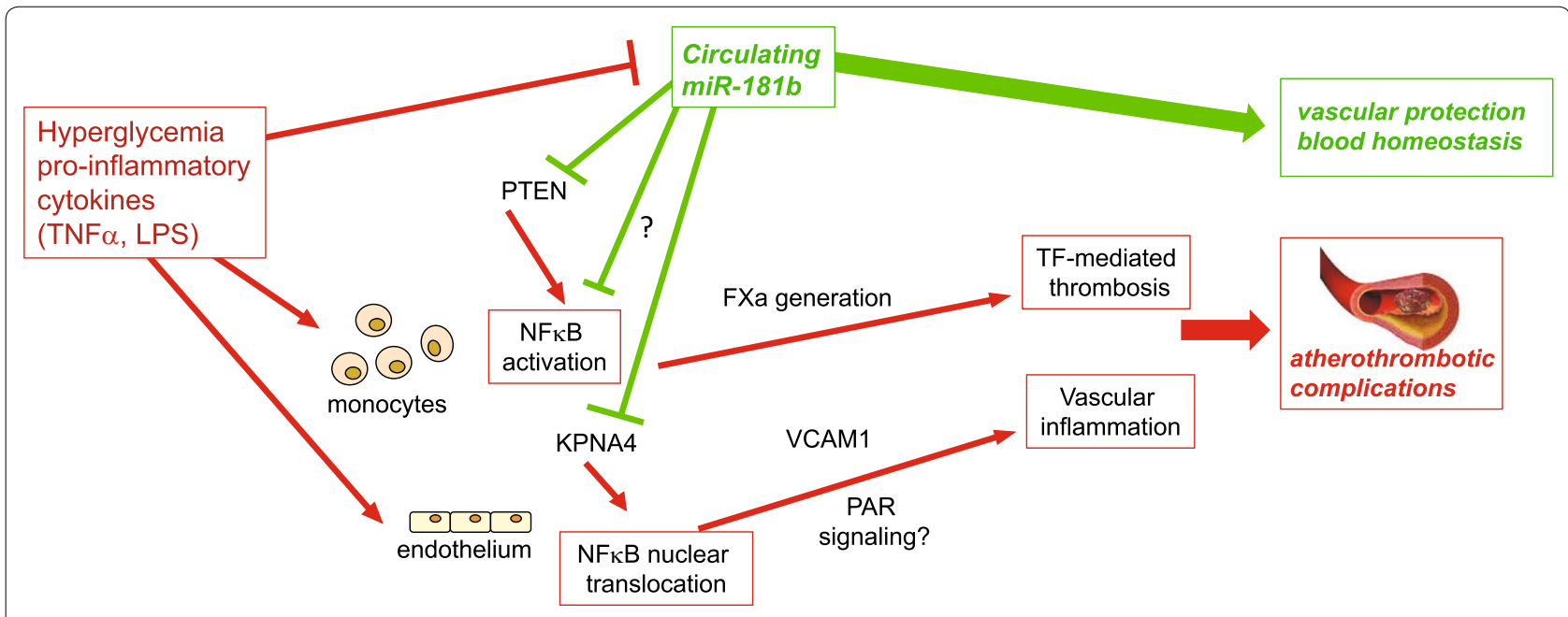

Fig. 6 Role of miR-181b in vascular homeostasis 
explore the prognostic value of miR-181b for prediction of major adverse cardiac events.

\section{Supplementary information}

Supplementary information accompanies this paper at https://doi. org/10.1186/s12933-020-0993-z.

Additional file 1: Table S1. Characteristics of healthy controls. BMI body mass index, HbA1c glycated hemoglobin. Values presented are means $\pm S D$, median $[\mathrm{IQR}]$ or percentage.

Additional file 2: Figure S1. Vascular inflammation reduces miR-181b expression and induces TF and VCAM1 expression in HMEC-1. HMEC-1 were cultured overnight and exposed to high glucose or stimulated with $10 \mathrm{ng} / \mathrm{mL}$ of TNFa. Treatment with $25 \mathrm{mM}$ glucose (A) and TNFa (B) caused a reduction of miR-181 b expression, while mRNA expression of asTF (C), fTTF (D), and VCAM1 (E) was induced after $4 \mathrm{~h}$ and $6 \mathrm{~h}$ post stimulation. Western blot analysis showed the protein induction of asTF (F), fTF (G), and VCAM1 $(\mathrm{H})$ following 6 h or $24 \mathrm{~h}$ TNFa stimulation. $n \geq 3$, $p$-values by ANOVA test with Dunn's multiple comparison post hoc test.

Additional file 3: Figure S2. miR-181b reduces KPNA4 expression in HMEC-1. KPNA4 mRNA (A) and protein (B) expression in HMEC-1 transfected with a control mimic or miR-181b. $n \geq 3, p$-value by student's t test.

Additional file 4: Figure S3. Original western blot showing protein abundance of $\mathrm{NFkB}$, phospho-NFkB, histone 3, and GAPDH in nuclear and cytoplasmic extracts from THP-1 cell transfected with miR-181b or a control mimic under basal conditions or presence of LPS.

Additional file 5: Figure S4. No alteration of blood-borne TF activity in miR-181-/- animals. miR-181b expression in spleen tissue of wt and miR181-/- animals (A). MV-derived FXa generation (B) and TAT complexes (C) in plasma of wt and miR-181-/- animals stimulated with LPS for $4 \mathrm{~h}$. $\mathrm{n}=4-5$ animals per group, comparison by Mann Whitney or student's $\mathrm{t}$ test.

Additional file 6: Figure S5. Healthy controls have higher miR-126 but not miR-181 b expression than patients with type 2 diabetes. Expression of miR-181b (A) or miR-126 (B) in heathy controls and the cohort with poorly controlled type 2 diabetes. $n=20$ for controls, $n=46$ for poorly controlled diabetes, p-values by Mann Whitney test.

\section{Abbreviations}

asTF: Alternatively-spliced tissue factor; BMDM: Bone marrow-derived macrophages; fITF: Full-length tissue factor; HMEC: Human microvascular endothelial cells; LPS: Lipopolysaccharide; miR: microRNA; TNF: Tumor necrosis factor; VCAM1: Vascular cell adhesion molecule 1.

\section{Acknowledgements}

We thank Kerstin Kamprath for the technical support.

\section{Authors' contributions}

MarcoW and MarioW designed the study, carried out the assays, performed statistical analyses, and drafted the manuscript. MS performed the BMDM experiments and the FXa measurements in murine blood, TT, LT, JF, AC, and AD carried out experiments and edited the manuscript. AK and SW provided the miR-181 ko animals and helped conducting experiments using mouse tissues. WR, CS, and DT participated in the design of the study and edited manuscript. UR designed the study and edited the manuscript. All authors read and approved the final manuscript.

\section{Funding}

This work was supported by a research Grant of the German Research Foundation (RA 799/5-1).

\section{Availability of data and materials}

The datasets used during the study are available from the corresponding author on reasonable request.
Ethics approval and consent to participate

The study protocol was approved by the local Ethics Committee and was performed in accordance to the ethics principles in the Declaration of Helsinki. All participants signed a written informed consent.

\section{Consent for publication}

Not applicable.

\section{Competing interests}

The authors declare that they have no competing interests.

\section{Author details}

${ }^{1}$ Charité Centrum 11, Department of Cardiology, Charité - Universitätsmedizin Berlin, Campus Benjamin Franklin, Hindenburgdamm 30, 12200 Berlin, Germany. ${ }^{2}$ Research Centre Immunology and Institute of Medical Microbiology and Hygiene, University of Mainz Medical Centre, Mainz, Germany. ${ }^{3}$ Center for Thrombosis and Hemostasis, University Medical Center of the Johannes Gutenberg University, Mainz, Germany. ${ }^{4}$ Heart and Diabetes Center NRW, Ruhr University of Bochum, Bad Oeynhausen, Germany. ${ }^{5}$ Institute for Molecular Medicine, Goethe-University Frankfurt, Frankfurt am Main, Germany.

Received: 6 November 2019 Accepted: 26 January 2020

Published online: 17 February 2020

\section{References}

1. Beckman JA, Creager MA. Vascular complications of diabetes. Circ Res. 2016;118(11):1771-85.

2. Schuette C, Steffens D, Witkowski M, Stellbaum C, Bobbert P, Schultheiss $\mathrm{HP}$, et al. The effect of clopidogrel on platelet activity in patients with and without type-2 diabetes mellitus: a comparative study. Cardiovasc Diabetol. 2015;14:15.

3. Witkowski M, Landmesser $U$, Rauch U. Tissue factor as a link between inflammation and coagulation. Trends Cardiovasc Med. 2016;26(4):297-303

4. Witkowski M, Rauch U. Letter to the editor: tissue factor of endothelial origin: Just another brick in the wall? Trends Cardiovasc Med. 2017:27(2):155-6.

5. Eisenreich A, Bogdanov VY, Zakrzewicz A, Pries A, Antoniak S, Poller $W$, et al. Cdc2-like kinases and DNA topoisomerase I regulate alternative splicing of tissue factor in human endothelial cells. Circ Res. 2009;104(5):589-99.

6. Bogdanov VY, Osterud B. Cardiovascular complications of diabetes mellitus: the tissue factor perspective. Thromb Res. 2010;125(2):112-8.

7. Weithauser A, Bobbert P, Antoniak S, Bohm A, Rauch BH, Klingel K, et al. Protease-activated receptor-2 regulates the innate immune response to viral infection in a coxsackievirus B3-induced myocarditis. J Am Coll Cardiol. 2013;62(19):1737-45.

8. Weithauser A, Witkowski M, Rauch U. The role of protease-activated receptors for the development of myocarditis: possible therapeutic implications. Curr Pharm Des. 2016;22(4):472-84.

9. Friebel J, Weithauser A, Witkowski M, Rauch BH, Savvatis K, Dorner A, et al. Protease-activated receptor 2 deficiency mediates cardiac fibrosis and diastolic dysfunction. Eur Heart J. 2019;40(40):3318-32.

10. Ebert J, Wilgenbus P, Teiber JF, Jurk K, Schwierczek K, Dohrmann M, et al. Paraoxonase-2 regulates coagulation activation through endothelial tissue factor. Blood. 2018;131(19):2161-72.

11. Furlan-Freguia C, Marchese P, Gruber A, Ruggeri ZM, RufW. P2X7 receptor signaling contributes to tissue factor-dependent thrombosis in mice. J Clin Investig. 2011;121(7):2932-44.

12. Hisada Y, Alexander W, Kasthuri R, Voorhees P, Mobarrez F, Taylor A, et al. Measurement of microparticle tissue factor activity in clinical samples: a summary of two tissue factor-dependent FXa generation assays. Thromb Res. 2016;139:90-7.

13. Pawlinski R, Wang JG, Owens AP 3rd, Williams J, Antoniak S, Tencati $M$, et al. Hematopoietic and nonhematopoietic cell tissue factor activates the coagulation cascade in endotoxemic mice. Blood. 2010;116(5):806-14.

14. Rothmeier AS, Marchese P, Petrich BG, Furlan-Freguia C, Ginsberg $\mathrm{MH}$, Ruggeri ZM, et al. Caspase-1-mediated pathway promotes 
generation of thromboinflammatory microparticles. J Clin Investig. 2015;125(4):1471-84.

15. Rauch U, Bonderman D, Bohrmann B, Badimon JJ, Himber J, Riederer MA, et al. Transfer of tissue factor from leukocytes to platelets is mediated by CD15 and tissue factor. Blood. 2000;96(1):170-5.

16. Sambola A, Osende J, Hathcock J, Degen M, Nemerson Y, Fuster V, et al. Role of risk factors in the modulation of tissue factor activity and blood thrombogenicity. Circulation. 2003;107(7):973-7.

17. Jakob P, Kacprowski T, Briand-Schumacher S, Heg D, Klingenberg R, Stahli $\mathrm{BE}$, et al. Profiling and validation of circulating microRNAs for cardiovascular events in patients presenting with ST-segment elevation myocardial infarction. Eur Heart J. 2017:38(7):511-5.

18. Pordzik J, Jakubik D, Jarosz-Popek J, Wicik Z, Eyileten C, De Rosa S, et al. Significance of circulating microRNAs in diabetes mellitus type 2 and platelet reactivity: bioinformatic analysis and review. Cardiovasc Diabetol. 2019;18(1):113

19. Ghosh N, Katare R. Molecular mechanism of diabetic cardiomyopathy and modulation of microRNA function by synthetic oligonucleotides. Cardiovasc Diabetol. 2018;17(1):43.

20. Witkowski M, Weithauser A, Tabaraie T, Steffens D, Krankel N, Witkowski $M$, et al. Micro-RNA-126 reduces the blood thrombogenicity in diabetes mellitus via targeting of tissue factor. Arterioscler Thromb Vasc Biol. 2016;36(6):1263-71.

21. Witkowski M, Tabaraie T, Steffens D, Friebel J, Dorner A, Skurk C, et al. MicroRNA-19a contributes to the epigenetic regulation of tissue factor in diabetes. Cardiovasc Diabetol. 2018;17(1):34

22. Sun X, Icli B, Wara AK, Belkin N, He S, Kobzik L, et al. MicroRNA-181b regulates NF-kappaB-mediated vascular inflammation. J Clin Investig. 2012;122(6):1973-90

23. Henao-Mejia J, Williams A, Goff LA, Staron M, Licona-Limon P, Kaech SM, et al. The microRNA miR-181 is a critical cellular metabolic rheostat essential for NKT cell ontogenesis and lymphocyte development and homeostasis. Immunity. 2013;38(5):984-97.

24. Luyendyk JP, Schabbauer GA, Tencati M, Holscher T, Pawlinski R, Mackman $\mathrm{N}$. Genetic analysis of the role of the PI3K-Akt pathway in lipopolysaccharide-induced cytokine and tissue factor gene expression in monocytes/ macrophages. J Immunol. 2008;180(6):4218-26.

25. Lin J, He S, Sun X, Franck G, Deng Y, Yang D, et al. MicroRNA-181 b inhibits thrombin-mediated endothelial activation and arterial thrombosis by targeting caspase recruitment domain family member 10. FASEB J. 2016;30(9):3216-26.

26. Chou J, Mackman N, Merrill-Skoloff G, Pedersen B, Furie BC, Furie B. Hematopoietic cell-derived microparticle tissue factor contributes to fibrin formation during thrombus propagation. Blood. 2004;104(10):3190-7.

27. Day SM, Reeve JL, Pedersen B, Farris DM, Myers DD, Im M, et al. Macrovascular thrombosis is driven by tissue factor derived primarily from the blood vessel wall. Blood. 2005;105(1):192-8.

28. Sun X, Lin J, Zhang Y, Kang S, Belkin N, Wara AK, et al. MicroRNA-181 b improves glucose homeostasis and insulin sensitivity by regulating endothelial function in white adipose tissue. Circ Res. 2016;118(5):810-21.

29. Ziętara N, Łyszkiewicz M, Witzlau K, Naumann R, Hurwitz R, Langemeier J, et al. Critical role for miR-181a/b-1 in agonist selection of invariant natural killer T cells. Proc Natl Acad Sci. 2013;110(18):7407.

30. Fang Y, Shi C, Manduchi E, Civelek M, Davies PF. MicroRNA-10a regulation of proinflammatory phenotype in athero-susceptible endothelium in vivo and in vitro. Proc Natl Acad Sci USA. 2010:107(30):13450-5.
31. Harris TA, Yamakuchi M, Ferlito M, Mendell JT, Lowenstein CJ. MicroRNA-126 regulates endothelial expression of vascular cell adhesion molecule 1. Proc Natl Acad Sci USA. 2008:105(5):1516-21.

32. Sun X, He S, Wara AKM, Icli B, Shvartz E, Tesmenitsky Y, et al. Systemic delivery of microRNA-181b inhibits nuclear factor-kappaB activation, vascular inflammation, and atherosclerosis in apolipoprotein E-deficient mice. Circ Res. 2014;114(1):32-40.

33. He Y, Ding Y, Liang B, Lin J, Kim TK, Yu H, et al. A systematic study of dysregulated microRNA in type 2 diabetes mellitus. Int J Mol Sci. 2017;18(3):456

34. Zampetaki A, Kiechl S, Drozdov I, Willeit P, Mayr U, Prokopi M, et al. Plasma microRNA profiling reveals loss of endothelial miR-126 and other microRNAs in type 2 diabetes. Circ Res. 2010;107(6):810-7.

35. Jacovetti C, Matkovich SJ, Rodriguez-Trejo A, Guay C, Regazzi R. Postnatal beta-cell maturation is associated with islet-specific microRNA changes induced by nutrient shifts at weaning. Nat Commun. 2015;6:8084.

36. Sanchez PL, Morinigo JL, Pabon P, Martin F, Piedra I, Palacios IF, et al. Prognostic relations between inflammatory markers and mortality in diabetic patients with non-ST elevation acute coronary syndrome. Heart. 2004:90(3):264-9.

37. Yang M, Tian M, Zhang X, Xu J, Yang B, Yu J, et al. Role of the JAK2/STAT3 signaling pathway in the pathogenesis of type 2 diabetes mellitus with macrovascular complications. Oncotarget. 2017;8(57):96958-69.

38. Chantrathammachart P, Mackman N, Sparkenbaugh E, Wang JG, Parise LV, Kirchhofer D, et al. Tissue factor promotes activation of coagulation and inflammation in a mouse model of sickle cell disease. Blood. 2012;120(3):636-46.

39. Mega JL, Braunwald E, Wiviott SD, Bassand JP, Bhatt DL, Bode C, et al. Rivaroxaban in patients with a recent acute coronary syndrome. $N$ Engl J Med. 2012;366(1):9-19.

40. Friebel J, Witkowski M, Rauch U. Treating the unstable atherosclerotic plaque by targeting activated factor $X$-anticoagulation and beyond. Circ J. 2015;79(11):2329-31.

41. Njock MS, Cheng HS, Dang LT, Nazari-Jahantigh M, Lau AC, Boudreau E, et al. Endothelial cells suppress monocyte activation through secretion of extracellular vesicles containing antiinflammatory microRNAs. Blood. 2015;125(20):3202-12.

42. Guha M, Mackman N. The phosphatidylinositol 3-kinase-Akt pathway limits lipopolysaccharide activation of signaling pathways and expression of inflammatory mediators in human monocytic cells. J Biol Chem. 2002:277(35):32124-32.

43. Wilcox JN, Smith KM, Schwartz SM, Gordon D. Localization of tissue factor in the normal vessel wall and in the atherosclerotic plaque. Proc Natl Acad Sci USA. 1989;86(8):2839-43.

44. Szotowski B, Goldin-Lang P, Antoniak S, Bogdanov VY, Pathirana D, Pauschinger $\mathrm{M}$, et al. Alterations in myocardial tissue factor expression and cellular localization in dilated cardiomyopathy. J Am Coll Cardiol. 2005;45(7):1081-9.

\section{Publisher's Note}

Springer Nature remains neutral with regard to jurisdictional claims in published maps and institutional affiliations.

Ready to submit your research? Choose BMC and benefit from

- fast, convenient online submission

- thorough peer review by experienced researchers in your field

- rapid publication on acceptance

- support for research data, including large and complex data types

- gold Open Access which fosters wider collaboration and increased citations

- maximum visibility for your research: over 100M website views per year

At $\mathrm{BMC}$, research is always in progress.

Learn more biomedcentral.com/submissions 